\title{
Introductory Overview: IATSIC Symposium, WJS
}

\author{
Timothy Craig Hardcastle ${ }^{1,2,3}$
}

Published online: 1 March 2017

(C) Société Internationale de Chirurgie 2017

Trauma is a major scourge in the developing world with almost $90 \%$ of trauma-related deaths occurring in low- and middle-income countries (LMICs) [1]. A major part of the mortality is at the scene, and preventative strategies can address this burden of disease; however, a second surge in mortality occurs in the post-acute period, particularly in the critically ill who end up in the ICU.

Grimes recently showed that the treatment of the injured is a cost-effective exercise when compared to the treatment of HIV-AIDS [2], and thus, this symposium is timely as it aims to address aspects relevant to both the developed economies and LMICs.

Critical care is more than just a place; rather, it is a care concept. Critical care of the severely injured begins in the emergency department and continues through the operative phase of trauma care (not specifically addressed in this symposium), and in later ICU or ward care. This IATSIC Symposium aims to highlight some of the major aspects of management of the critically ill. Firstly, touching on aspects relevant to the acute care phase, Pillay addresses issues related to safe rapid sequence intubation (with a focus on the LMIC), while Hardcastle and colleagues address the practical aspects around optimal ventilation (from admission to the later ICU phase) [3, 4]. Both of these articles aim to highlight how erroneous extrapolation of research in a vastly different environment is often

Timothy Craig Hardcastle

hardcastle@ukzn.ac.za; timothyhar@ialch.co.za

1 Inkosi Albert Luthuli Central Hospital, 800 Vusi Mzimela Rd, Mayville 4091, South Africa

2 Department of Surgery, University of KwaZulu-Natal, Congella, Durban, South Africa

3 PostNet 27, Private Bag X05, Malvern 4055, KZN, South Africa wrongly used to derive treatment guidelines for the early resuscitation phase of care. This inappropriate use of "evidence-based medicine" may lead to poorer outcomes [5].

These two papers highlight the need for safe induction agents, appropriate use of muscle relaxation and the need for a different ventilation approach in the early phase of resuscitation, where reversal of metabolic acidosis is paramount, compared to the patient with severe lung pathology later on in the ICU phase of care [3,4]. A recent systematic review has drawn similar conclusions on the aspects around optimal ventilation [6].

The issues around fluid therapy options, debates around the fluid types and interpretation of fluid balance are addressed with a particular bent toward the LMICs by Wise and co-authors [7]. This is a very comprehensive overview, examining the basics, and most of the issues are discussed in light of the limited access to blood transfusion in LMICs where it is often necessary to consider other options, such as colloids or blood substitutes, despite the limited availability of these drugs. While the colloids do not carry oxygen, they do allow for less edema and may reduce bowel-anastomotic leaks when compared to the exclusive use of crystalloids, which is often pushed as the optimal choice; however, this has been poorly studied to date, not to mention the proposed beneficial effect on the glycocalyx of colloids [8]. More recent work suggests that the effect on renal dysfunction in patients receiving colloids may have been overstated [9]. Blood substitutes were, until recently, considered anathema in the developed world environment, but the use of Hemopure ${ }^{\circledR}$ remains an option as an oxygen bridge in the developing world.

Once the patient has survived all of the phases of resuscitation, surgical intervention and usual ICU care there will be those who remain in a state of refractory 
hypoxia. For this group of patients, the advanced modes of ventilation may not work and extracorporeal oxygenation remains the only alternative. This came into its own with the SARS outbreaks, but some recent work has shown that selected trauma patients may benefit as well. David Zonies, from Oregon, shares an overview of the literature and some personal insights into the use of this fairly new therapeutic option, which is, unfortunately, somewhat restricted to the higher income country scenario at present [10]. As the outcomes and potential advantages of this concept become clearer and devices become more cost-effective, then the LMIC countries may find a place for this therapy.

Sepsis remains the major cause of late death in the trauma patient [11]. Ramsamy and co-workers give a useful overview of the need for circumspection in the use of antimicrobials and the need for good surveillance, antibiotic stewardship and rational prescribing [12]. To not heed their warning will lead to further antimicrobial resistance, increasing mortality and frustration among clinicians whose hands are tied due to a lack of available drugs to treat sepsis in the near future. This is not only a problem in the high-income developed countries, but a rapidly emerging problem in LMICs too.

In conclusion, we hope that the topics covered in this symposium are found to be both useful for daily practice and relevant to optimizing patient care, wherever the emergency physician, trauma surgeon or anesthesiologist and intensivist are based. Some of these aspects may be particularly pertinent to physicians from high-income countries doing developmental outreach work in LMICs. Furthermore, the articles will provide good educational overviews for surgeons-in-training.

\section{References}

1. Lozano R, Naghavi M, Foreman K et al (2013) Global and regional mortality from 235 causes of death for 20 age groups in 1990 and 2010: a systematic analysis for the Global Burden of Disease study 2010. Lancet 380:2095-2128

2. Grimes CE, Henry JA, Maraka J et al (2014) Cost-effectiveness of surgery in low- and middle-income countries: a systematic review. World J Surg 38:252-263. doi:10.1007/s00268-013-2243-y

3. Pillay L, Hardcastle TC (2017) Collective review of the status of rapid sequence intubation drugs of choice in trauma in low and middle income settings (prehospital, emergency department and operating room setting). World J Surg. doi:10.1007/s00268-0163712-x

4. Hardcastle TC, Muckart DJJ, Maier RV (2017) Ventilation in trauma patients: the first $24 \mathrm{~h}$ is different! World J Surg. doi:10. 1007/s00268-016-3530-1

5. Muckart DJJ (2013) Evidence-based medicine-are we boiling the frog? S Afr Med J 103:447-448

6. Guo L, Wang W, Zhao N et al (2016) Mechanical ventilation strategies for intensive care unit patients without acute lung injury or acute respiratory distress syndrome: a systematic review and network meta-analysis. Crit Care 20:226

7. Wise R, Faurie M, Malbrain M, Hodgson RE (2017) Strategies for intravenous fluid resuscitation in trauma patients. World $\mathrm{J}$ Surg. doi:10.1007/s00268-016-3865-7

8. Chappell D, Jacob M (2014) Role of the glycocalyx in fluid management: small things matter. Best Pract Res Clin Anaesthesiol 28(3):227-234

9. Annane D, Slami S, Jaber S et al (2013) Effects of fluid resuscitation with colloids vs. crystalloids on mortality in critically ill patients presenting with hypovolemic shock: the cristal randomized trial. J Am Med Assn 310(17):1809-1817

10. Zonies D (2017) Current and future states for ECMO in high-risk surgical patients. World J Surg. doi:10.1007/s00268-016-3586-y

11. Sobrino J, Shafti S (2013) Timing and causes of death after injuries. Proc (Bayl Univ Med Cent) 26(2):120-123

12. Ramsamy Y, Hardcastle TC, Muckart DJ (2017) Surviving sepsis in the intensive care unit-trauma is different. World J Surg. doi:10.1007/s00268-016-3531-0 